\title{
Le Développement De La Compétence Interculturelle Dans L'enseignement Du FLE: Un Exemple d'Application
}

\section{Yabancı Dil Olarak Fransızca Öğretiminde Kültürlerarası İletişim Becerisi Gelişimi: Bir Uygulama Örneği}

\author{
Gizem KÖŞKER ${ }^{1}$ \\ ${ }^{1}$ Dr. Öğretim Üyesi, Yabancı Diller Eğitimi Bölümü, Eğitim Fakültesi, Anadolu Üniversitesi, \\ Türkiye, gizemkosker@anadolu.edu.tr, (https://orcid.org/0000-0002-0115-9756)
}

Geliş Tarihi: 24.05.2021

Kabul Tarihi: 04.11.2021

\section{RÉSUMÉ}

La communication est l'outil le plus fonctionnel que les êtres humains utilisent pour interagir avec d'autres individus dans la société, pour comprendre leurs modes de vie et leurs valeurs. Les codes culturels entrent en jeu pour percevoir les composantes qui sous-tendent les comportements et pour transmettre les réflexions culturelles. Le rôle de l'interaction interculturelle vient donc au premier plan pour une communication efficace. L'Approche Actionnelle favorise ensemble de la langue et de la culture dans l'enseignement des langues étrangères. Celle-ci vise à développer la compétence interculturelle chez les individus. Alors que la communication interculturelle soutient des valeurs universelles, elle vise également à protéger la diversité culturelle. Dans cette étude, le développement de la compétence interculturelle des apprenants du FLE a été analysé à travers le film "Les Choristes". Ce film abordant le système éducatif français, il montre des exemples tels que l'environnement scolaire, la relation enseignant-élève, l'autorité. À la fin de l'étude, il a été déterminé que les éléments culturels du film offrent une source appropriée aux apprenants pour à la fois explorer la société française et pour sensibiliser à la culture source. Cette perspective est censée soutenir une vision ouverte que tout apprenant de langue devrait avoir.

Mots-clés : Documents authentiques, approche interculturelle, enseignement du FLE.

ÖZ

İletişim, insanlığın toplum içinde diğer bireylerle etkileşim kurmak, yaşam tarzları ve değerlerini anlamak için kullandığı en işlevsel araçtır. Bireylerin davranışları altında yatan bileşenleri doğru algılamak ve kendi kültürel yansımalarını aktarmada kültürel kodlar devreye girmektedir. $\mathrm{Bu}$ noktada kültürlerarası etkileşimin, iletişim sağlamadaki rolü ön plana çıkmaktadır. Günümüz yabancı dil öğretiminde, dil ve kültürü birlikte ele alan ve öğrenenlerde kültürlerarası iletişim becerisi geliştirmeyi amaçlayan eylem odaklı yaklaşım kullanılmaktadır. Kültürlerarası iletişim kültürel farklılıklara saygı, hoşgörü gibi insani ve evrensel değerleri desteklerken aynı zamanda kültürel çeşitliliği korumayı amaçlamaktadır. Bu çalışmada dili öğretilen toplumu farklı boyutları ile gözlemleme imkânı sunan "Koro" filminde hedef kültürle ilgili aktarılan örnekler üzerinden, yabancı dil olarak Fransızca öğrenenlerin kültürlerarası iletişim becerisi gelişimine katkıları incelenmiştir. Yabancı dil dersinde kazandırılması hedeflenen beceriler konusunda film üzerinden ilerlemenin, öğrenenler için klasik, geleneksel ders işleyişine göre daha zevkli ve ilgi çekici olduğu düşünülmektedir. Çalışmada tercih edilen film Fransız eğitim sistemi konusunu ele alırken izleyiciye okul ortamı, ders içerikleri, öğretmen öğrenci ilişkisi, otorite, ceza gibi zengin örnekler sunmaktadır. Çalışma sonunda filmdeki kültürel örneklerin, öğrenenlerin hem Fransız toplumunu keşif hem de kendi değerleri üzerine düşünerek, kaynak kültürde farkındalık için elverişli ortam sunduğu gözlenmiştir. Bu bakış açısının her dil öğrenenin sahip olması gereken açık bir dünya görüşünü desteklediği düşünülmektedir.

Anahtar Kelimeler: Özgün dokümanlar, kültürlerarası yaklaşım, yabancı dil olarak Fransızca öğretimi. 


\section{INTRODUCTION}

La communication n'est pas qu'un échange d'information qui sert à l'interaction avec d'autres individus, à la compréhension de leur mode de vie, de leurs croyances, de leurs valeurs, de leurs comportements, etc., elle permet également de s'exprimer, de présenter son identité toute subjective. Chaque individu emprunte et prête quelque chose à travers la communication (Byram \& Planet, 2000). Dans ce cas, il ne suffit pas de limiter la communication à l'utilisation de la langue. Le processus de communication ne peut être réduit uniquement à des éléments verbaux.

Lors de la communication, la langue est l'intermédiaire qui permet de transmettre les caractéristiques et la culture d'une société de la manière la plus précise. La culture permet pareillement d'expliquer la langue à travers des valeurs communes et elle se développe dans un processus historique. Celle-ci évolue avec le temps en s'adaptant aux conditions de l'époque. Les codes culturels se transmettent de génération en génération, et donc la langue assure la continuité de la culture.

Apprendre une langue étrangère, donc, c'est essayer de comprendre la vision du monde, la pensée, la perception et les systèmes de valeurs d'autres sociétés dans le monde. Apprendre une langue étrangère, c'est essayer de comprendre le comportement sous-jacent des individus ainsi que les paroles des individus qui composent une société, et rencontrer différentes manières de penser et de vivre. Avec cette interaction, il s'agit d'aborder le monde avec une perspective plus respectueuse et tolérante.

Cicurel (2011) explique cette interaction didactique comme genre au sein des interactions sociales. Cependant, dans la mesure où l'enjeu de ces échanges se trouve du côté de la transmission d'objets de savoir et de savoir-faire, et où le discours se construit dynamiquement à travers des structures temporelles afin de faciliter cette transmission, les travaux sur la classe sont aussi à situer dans l'espace de la recherche en didactique.

À partir des années 90, une nouvelle approche, dite actionnelle, focalisée sur la dimension (inter)culturelle des langues donne la priorité à l'acquisition de compétences communicatives qui prend une place importante dans la didactiques des langues étrangères. L'auteur explique cette compétence comme la capacité à gérer les phénomènes de contact entre cultures différentes lorsque l'on communique avec des étrangers dans le cadre de rencontres ponctuelles, d'échanges, de voyages ou de séjours touristiques, en particulier en repérant les incompréhensions causées par ses représentations préalables de la culture de l'autre, et les mécompréhensions causées par les interprétations faites sur la base de son propre référentiel culturel (Puren, 2006).

Dans l'approche actionnelle, l'utilisateur de la langue est considéré comme acteur social qui va agir dans les grands domaines de la vie sociale (personnel, éducationnel, professionnel, public) » où il s'exprime et agit différemment en fonction des contextes et ces contextes engendrent à leur tour des situations (Girardet, 2011). La langue est considérée comme outil collaboratif pour une action commune dans l'approche actionnelle. L'enseignement de la langue cible en fonction du contexte social offre également l'opportunité de reconnaître et d'apprendre les différents usages de la langue sur le plan sociétal. L'objectif est que les apprenants n'aient aucun problème face à différentes utilisations de la langue cible dans la vie réelle.

Il est mentionné quatre types de savoirs qu'une approche actionnelle peut requérir pour l'acquisition des compétences communicatives et des compétences générales dans l'apprentissage d'une langue (CECR, 2001):

- « les savoirs : connaissances à acquérir issues des regards croisés (comment chacun apparait dans l'optique de l'autre) ; 
- les savoir-être : attitudes à développer : relativiser son système de références culturelles, s'ouvrir à l'altérité, se décentrer ;

- les savoir-faire : aptitudes à établir un contact et une relation entre les cultures, jouer un rôle d'intermédiaire culturel, gérer les malentendus culturels et être capable d'effectuer un retour réflexif sur sa propre culture, etc. ;

- les savoir-apprendre : mobilisation de tous les savoirs précédents pour découvrir de nouvelle expériences et de nouveaux comportements, valeurs, croyances, être disposé à découvrir l'autre. » (CECR, 2001).

Il serait donc indispensable de se rendre compte de l'aspect pragmatique de la langue dans l'enseignement/l'apprentissage de la langue, ainsi que de la place et des contributions des compétences culturelles qui ne peuvent être ignorées.

La notion de culture est un concept très profond qui est inclus dans le champ d'étude de diverses disciplines comme anthropologie, psychologie, relations internationales, éducation, etc. car la culture est une structure multi-composants. Dans cette étude, la signification la plus claire du mot culture est prise comme base. Tylor (1871, cité par Rocher, 1995) explique que la culture dans son sens ethnographique étendu, est cet ensemble complexe qui inclut la connaissance, la croyance, l'art, la morale, le droit, la coutume et toutes autres capacités et habitudes acquises par l'homme en tant que membre d'une société.

Quant à l'interculturel, il pourrait généralement être défini comme « l'appréciation des différences culturelles dans le but de comprendre les lois sociales, psychologiques et linguistiques qui régissent les rapprochements et favorisent le respect des cultures en contact» (Cazabon, 1992). Cette appréciation comprend les moyens pour aborder les éventuels conflits afin de pouvoir en dégager une négociation équitable pour tous.

La compétence de communication inclut par principe des composantes socioculturelles que l'apprenant doit connaître lors de tout échange. Ce qui revient à dire que l'acquisition des compétences communicatives s'effectue à travers des interactions verbales et non-verbales qui reflètent des valeurs, des artefacts, des implicites, etc. d'une culture (Windmüller, 2011). L'acquisition des compétences communicatives garantissent que les expressions à privilégier dans l'utilisation de la langue sont utilisées de manière significative dans différents environnements, sur place et à temps. En bref, les compétences communicatives visent à créer un environnement de communication idéal. Une communication idéale est de transmettre le message à autrui de la manière la plus correcte, sans malentendu.

Pour une communication idéale, l'interculturalité fonctionne comme une analyse critique des événements quotidiens de la vie. Il sert à donner un sens au concept de multiculturalisme conformément à la structure du monde d'aujourd'hui et à le refléter positivement sur les relations sociales quotidiennes. Basée sur la communication interpersonnelle, l'approche interculturelle offre un environnement d'interaction pacifique et efficace.

La compétence interculturelle recentre le sujet et prend une position (inter)subjective et dialogique (concernant tous les états d'expressions dans la dimension humaine comme l'éphémère, l'aléatoire, la complexité, etc. ». La compétence interculturelle, donc, comprend les dimensions sociologique et anthropologique dans les échanges langagiers (Abdallah-Pretceille, 1996).

Dans ce cadre, la compétence interculturelle vise à la reconstruction consciente de l'identité dans la relation avec l'altérité. En d'autres termes, l'individu prend la conscience de ses propres valeurs et accepte l'existence des valeurs de l'Autre (Chaves et al. 2012). L'interculturalité développe l'empathie en s'éloignant de l'ethnocentrisme et elle accepte les individus avec leurs différences et leurs similitudes. 
L'outil le plus approprié pour développer ces compétences en communication interculturelle est le document authentique, qui est un échantillon de discours oral ou écrit présenté à l'apprenant sous une forme originale dans le respect du canal d'origine et du médium, et dans le souci de restituer sa forme originale dans ses moindres détails. Un document authentique est favorable pour ne pas tromper l'apprenant sur la marchandise en le confrontant à des textes fabriqués pour la bonne cause et pour permettre à l'apprenant de se livrer à une consommation sociale du document et non à une consommation scolaire (Delhaye, 2003).

L'objectif de cette étude est de préparer un exemple d'application focalisé sur l'aspect inter(culturel) dans l'enseignement du FLE. Pour ce faire, il a été choisi un film qui reflete la société française à travers une histoire d'un internat. À partir des principes, des objectifs et des démarches indiqués de l'approche interculturelle, une fiche pédagogique est organisée pour les cours de français langue étrangère. Via cet exemple d'application, on vise à développer la compétence interculturelle chez les apprenants du FLE.

\section{PUBLIC et DOCUMENT}

Le public cible de cette étude est constitué des étudiants âgés de 18 à 22 ans dans le département du FLE. Ils ont de niveau B1 selon les critères du Cadre européen commun de référence pour les langues. Le film sélectionné pour l'étude a été déterminé en tenant compte du niveau de langue du public cible, leur âge et leur intérêts communs. Il propose de nombreux objets culturels à la fois auditifs et visuels. Le film sélectionné s'intitule : "Les Choristes".

Ce film, coproduit en France et en Suisse, sorti en mars 2004, a été regardé avec une grande admiration à la fois dans le pays où il a été tourné et dans le monde entier. Ce film dans le genre drame musical dure 92 minutes sans générique. Le producteur du film s'appelle Christophe Barratier, scénariste et réalisateur français. Le compositeur du film est Bruno Coulais, qui offre au public une grande variété d'exemples de la musique française.

Le film décrit ce qui s'est passé après la Seconde Guerre mondiale dans un internat en 1948 en France où seuls les élèves de sexe masculin étaient éduqués. Il montre les événements qui se sont produits lorsqu'un professeur de musique au chômage, l'un des personnages principaux du film, a commencé à travailler dans cet internat. Dans le cas de l'enseignant au chômage, tout en donnant des indices sur la situation économique de la France, il critique également la compréhension pédagogique de la période jusqu'à ce jour.

Le film présente aussi les difficultés rencontrées en dépassant la compréhension de l'éducation classique à laquelle la société est habituée et les effets de l'utilisation de nouvelles méthodes éducatives. Il donne des exemples importants de la musique française. À travers l'internat, il offre des informations importantes sur l'architecture de la France, le style vestimentaire des individus et les habitudes quotidiennes. À travers de nombreux exemples de différents domaines (la morale, les relations humaines, etc.) de la société, il met en évidence l'importance des valeurs universelles telles que le respect de la différence et la tolérance adoptées par l'approche de la communication interculturelle.

Ainsi, dans la partie ci-dessous, les objectifs, le contenu et les activités du cours sont exposés en détail dans l'idée d'un développement des compétences interculturelles.

\section{EXEMPLE D'APPLICATION}

Niveau: B1

Public: Étudiants

Durée: 3 heures (45 min. +45 min. +45 min.) 
Matériel : Le film « Les Choristes » (92 min sans générique)

Thèmes : La connaissance de la culture cible avec une perspective interculturelle

Objectifs linguistiques

- Comprendre l'essentiel d'un film en version originale.

- Prendre part à une conversation concernant la vie quotidienne (par exemple éducation, art).

- Donner les raisons et explications des opinions.

- Comprendre des textes rédigés essentiellement dans une langue courante.

- Écrire un texte simple et cohérent sur des sujets traités.

Objectifs communicatifs

- Analyser des événements.

- Chercher et trouver des informations.

- Faire des critiques et donner son jugement.

- Échanger des opinions sur l'éducation française et celle de sa culture.

- Résumer, raconter.

Pré-activité (5 min.)

1. L'enseignant projette l'affiche du film au tableau et pose les questions ci-dessous :

1.1. De quel type de document s'agit-il ?

1.2. Quel est le genre du film?

1.3. Qu'est-ce que vous évoque le titre du film?

1.4. Comment les personnages apparaissent-ils ?

1.5. Quels sont les thèmes abordés?

2. Ce film a battu des records au box-office non seulement dans le pays où il a été tourné, mais partout dans le monde. Qu'en pensez-vous?

Activité

L'enseignant donne le synopsis du film aux apprenants. Ceux-ci le lisent individuellement

« En 1948, Clément Mathieu, professeur de musique sans emploi accepte un poste de surveillant dans un internat de rééducation pour mineurs; le système répressif appliqué par le directeur, Rachin, bouleverse Mathieu. En initiant ces enfants difficiles à la musique et au chant choral, Mathieu parviendra à transformer leur quotidien. $)^{*}$

1) Essayez de deviner le contenu du film (5 min.) film.

L'enseignant distribue les questions suivantes aux apprenants avant de faire visionner le

2) Regardez le film et répondez aux questions suivantes. (30 min)

a) Expliquez le titre du film ?

"https://www.allocine.fr/film/fichefilm_gen_cfilm=50325.html\#: :text=Synopsis,directeur\%2C $\% 20$ Rachin\%2C\%20bouleverse\%20Mathieu. 
b) Quelle est la première chose qu'on voit au début du film ?

c) Comment se passe la première rencontre de Clément Mathieu et le directeur ?

e) À quoi «Fond de l'étang » fait-il référence ?

f) Décrivez le bâtiment de l'école.

g) Quelle est l'approche principale du directeur aux élèves ?

h) Quelle est la première impression de Clément Mathieu sur les élèves ?

i) Comment le directeur aborde-t-il l'enfant envoyé du centre correctionnel ?

j) Aviez-vous bien deviné la fin du film ?

k) Êtes-vous content de cette fin ? Pourquoi ?

3) Quel est le message à transmettre à travers ce film ?

4) Relevez les éléments de références par rapport :

- À l'éducation

- À l'art

- À l'économie

- À l'histoire

- Au droit

- À la politique

- À la géographie

- À la mode

- À la morale

- Aux relations humaines

- À la vie quotidienne

6) Complétez le tableau ci-dessous.

Tableau 1. Descriptions Des Personnages

\begin{tabular}{ll}
\hline Personnages & $\begin{array}{c}\text { Description } \\
\text { Du Physique }\end{array}$ \\
\hline Clément & \\
Mathieu & \\
Le directeur & \\
Maxence & \\
Morhange & \\
Pépinot & \\
Le Querrec & \\
Mondain & \\
\hline
\end{tabular}


7) De quel personnage vous sentez-vous le plus proche ? Pourquoi ?

\section{Post-activité (Dévoir)}

Formez des groupes de trois personnes. Choisissez la scène du film qui vous impressionne le plus. Chacun se mettra dans la peau d'un personnage tout en conservant son identité. Jouez la scène devant la classe.

\section{CONCLUSION et DISCUSSION}

Les résultats de cette étude nous mènent à en conclure que les exemples culturels véhiculés par le film Les Choristes sont très favorables pour l'acquisition de la compétence interculturelle dans l'enseignement/ l'apprentissage du FLE. Les exemples présentant la culture cible à ceux qui apprennent le français comme langue étrangère peuvent être brièvement résumés comme suit:

Dans le film, les élèves chantent des chansons, tels que Vois sur ton chemin et La nuit, de Bruno Coulais, l'important compositeur de la musique classique française. Ces exemples donnés de l'art sont efficaces pour présenter l'art de la société cible aux apprenants. La compréhension de l'art d'une société donne des indices importants sur le mode de vie et sur le style de la perception de cette société.

Le directeur d'internat strict opprime les élèves avec ses pratiques traditionnelles. Avec son principe " action-réaction », l'approche éducative dictatoriale et son point de vue de l'élève sont reflétés. La vie en internat, les heures de repas et le rythme de sommeil sont montrés avec les sanctions sévères pour ceux qui ne respectent pas les règles. Seuls les élèves de sexe masculin sont admis à l'internat appelé «Fond de l'étang " qui symbolise le concept d'éducation. Les employés ne sont composés que d'hommes. Ces exemples donnent des signes importants sur le système éducatif français.

La scène dans laquelle un enfant (à travers le personnage Mondain) qui a commis un crime et amené de la prison à l'internat pour être réinséré dans la société, contient des informations sur les règles juridiques. En même temps, le préjugé contre quelqu'un qui a commis un crime est montré. Lors d'un vol à l'internat, le directeur accuse directement Mondain sans aucune preuve et le fait reconduire en prison par les gendarmes, alors qu'il est innocent. A la fin du film, Mondain s'évade de prison et brûle le bâtiment. Tous ces exemples présentent sur la morale et sur les pratiques juridiques de la société française. Notamment, la dernière scène du film, il a été accepté comme une critique sociologique de la culture cible pour les apprenants.

Les parents de Morhange, l'un des personnages principaux du film, sont divorcés. Ce que les enfants disent sur sa mère et sur le professeur Clément Mathieu reflète la vision de la famille, les relations entre les hommes et les femmes, et la tendance patriarcale dans la société.

Les dialogues avec l'équipe officielle en visite à l'internat, les efforts du directeur pour bien faire et des attitudes insincères sont les exemples intéressants. L'indifférence générale des invités au concert est un autre exemple important sur la politique de l'époque.

Le style vestimentaire des personnages et le recrutement du personnage principal, Mathieu reflètent le statut économique de la société française. Le restaurant où travaille la mère de Morhange, le lieu de l'internat, la communication interpersonnelles sont d'autres exemples qui traitent des dimensions différentes de la société française dans le film. Dans le cadre de l'approche actionnelle, les documents utilisés dans l'enseignement des langues étrangères assument le rôle d'outils à la fois linguistiques et culturels (Neves, 2015 ; Klett, 2012 ; Delhaye, 2003).

Aussi, le film sélectionné est convenable aux caractéristiques du public cible telles que l'âge des apprenants, leur niveau de langue et leur intérêts. Le fait que ce document soit à la fois 
visuel et auditif a été évalué comme un facteur positif pour augmenter la motivation et l'intérêt des apprenants.

Les activités préparées centralisant ce film, sont composées de trois étapes comme pré, pendant et post activités. Elles sont toutes conçues pour exercer différentes compétences linguistiques et culturelles chez les apprenants dans le cadre de la communication interculturelle. Chaque étape est donnée pour développer des compétences communicatives comme compréhension, respect, empathie, des valeurs soutenues par l'approche interculturelle (Bennett, 2004 ; Cazabon, 1992) ainsi que les quatre compétences langagières; expression orale, compréhension orale, compréhension écrite et expression écrite (Collés, 2013). Toutes les activités sont axées sur l'interaction, basée sur la compréhension d'autrui et le développement d'une sensibilité à ses propres caractéristiques culturelles. À travers les consignes rédigées, les apprenants ont également la possibilité de développer leurs compétences telles que le travail d'équipe, l'échange et le partage. Donc, l'application de cette étude, il a été consideré comme exemple fonctionnel qui active la compétence interculturelle, cinquième compétence destinée à être acquise par les apprenants en langue dans le cadre de l'approche actionnelle d'aujourd'hui (CECR, 2001).

Enseigner / apprendre une langue étrangère indépendamment de sa propre perception du monde ne semble pas logique et rend difficile la communication à travers cette langue. Le moyen le plus efficace d'éliminer cette situation est d'entrer dans l'espace de vie de la société dans laquelle cette langue est parlée. Dans le processus d'enseignement des langues étrangères, l'acquisition de la compétence (inter)culturelle qui soutient la communication et l'interaction entre différentes cultures, se démarque comme compétence importante qui devrait être acquise par chaque utilisateur d'une langue étrangère (Windmüller, 2011; Byram \& Planet, 2000 ; Abdallah Pretceille, 1996 ; Zarate, 1993). Les matériaux les plus utiles qui peuvent être utilisés pour développer cette compétence sont les documents authentiques qui transmettent directement aux apprenants la culture cible avec ses sous-éléments. Cependant les films offrent la possibilité de transmettre directement ces composants dans une intrigue dans toute leur diversité. Ils permettent aux apprenants de construire un pont entre la société qu'ils regardent et la leur. Alors que ce pont développe la sensibilité chez les apprenants aux différences culturelles, il enrichit également leur vision du monde.

\section{REFERENCES}

Abdallah Pretceille, M. (1996). Compétence culturelle, compétence interculturelle : pour une anthropologie de la communication. Le Français dans le monde, numéro spécial, janvier, 28-38.

Bennett, J.M. \& Bennett, M.J. (2004). Developping intercultural sensitivity: An intagrative approach to global and domestic diversity. Dans Landis D., Bennett J.M. et Bennett M.J. (Eds). Handbook of intercultural training (147-165). 3ème edition. Thousand Oaks, CA: SAGE.

Byram, M. \& Planet, M. T. (2000). Identité sociale et dimension européenne: la compétence interculturelle pour l'apprentissage des langues vivantes. Council of Europe.

Cazabon, B. (1992). L'interculturel et le respect des différences. Francophonies d'Amérique, 2, 73-86.

Chaves, R. M., Favier, L. et Pélissier, S. (2012). L'interculturel en classe. Presses universitaires de Grenoble.

Cicurel, F. (2011). De l'analyse des interactions en classe de langue à l'agir professoral : une recherche entre linguistique interactionnelle, didactique et théories de l'action. (page consultée le 28 juilliet 2021 https://journals.openedition.org/pratiques/1693). 
Collés, L. (2013). Passage des frontières. Études de didactique du français et de l'interculturel. Presses Universitaires de Louvain.

Conseil de l'Europe. (2001). Cadre européen commun de référence pour les langues: apprendre, enseigner, évaluer (CECR). coe. int.

Delhaye, O. (2003). « Le document authentique », http://gallika.net/spip.php?article42 (page consultée le 28 juilliet 2021).

Girardet, J. (2011). Enseigner le FLE selon une approche actionnelle : quelques propositions méthodologiques. In Conférence. Actes du XIIème colloque pédagogique de l'Alliance française de Sao Paolo. Brasil : Aliança Francesa São Paulo. http://www.vintagelanguage.fr/ressources/acte_conference_jacky_girardet.pdf (page consultée le 31 juillet 2021).

Klett, E. (2012). Le manuel pour enseigner une langue étrangère : Entre faiblesses et vertus. Synergies Venezuela, 7, 7-16.

Neves, L. (2015). Le rôle du manuel de FLE dans une approche (pluri) actionnelle. Revista Non Plus, 5, 37-49.

Rocher, G. (1995). Culture, civilisation et idéologie. Introduction à la sociologie. Montréal : Les Editions Hurtubise. http://societude.free.fr/Bibliographie/Syntheses/ROCHER\%20$\% 20$ culture\%20civilisation\%20ideologie.pdf (page consultée le 22 Janvier 2021).

Puren, C. (2006). De l'approche communicative à la perspective actionnelle. Le Français dans le monde, 347, 37-40.

Unesco. (1982). Mexico Mexico City Declaration on Cultural Policies World Conference on Cultural Policies Mexico City, 26 July - 6 August 1982. http://www.culturalrights.net/descargas/drets_culturals401.pdf (page consultée le 25 Janvier 2021).

Windmüller, F. (2011). Français langue étrangère (FLE): l'approche culturelle et interculturelle. Paris : Belin.

Zarate, G. (1993). Représentations de l'étranger et didactique des langues. Paris: Didier.

\section{GENIŞLETILMIŞ ÖZ}

İnsanı diğer canlılardan ayıran ve üstün tutan en önemli özelliğin düşünme yetisi olduğu bilinen bir gerçektir. Duygu ve düşünceleri aktarabilmeyi sağlayan iletişim becerisi insanlığa verilen bu artı özelliğin en önemli yansımalarından biridir. Bu noktada iletişim görüldüğü gibi sadece sıradan ve basit bir bilgi alışverişi değildir. İletişim süreci aynı zamanda bireyin toplum içinde var olabilmesine, diğer bireylerle etkileşim kurabilmesine ve yaşama uyum sağlayabilmesine yarayan en önemli aracıdır. İletişim becerisi, etkileşime girilen diğer bireyler vasıtası ile farklı düşünceleri, yaşam tarzlarını, değerleri ve davranışları anlayabilme becerisidir.

Bahsedilen bireysel farklılıkların altında yatan en temel belirleyici unsur ise kültür olarak görülmektedir. Bireyin toplum içindeki özgünlüğünü belirleyen ve onun diğerler bireylerden ayırt edilmesini sağlayan kimlik oluşumu da benzer şekilde kültürel kodlarla şekillenmektedir. Bireylerin dünyayı algılama ve yorumlama biçimi, davranışları, iletişim sırasında tercih ettikleri sözcükler bu kodlarla oluşmaktadır. Bu durumda dil ve kültür birbirinden ayrı düşünülmesi mümkün olmayan ve yaşam içinde birbiriyle paralel işleyen dinamik olgulardır.

Günümüz dünyasında bir yandan bilim ve teknoloji alanlarındaki hızına yetişilemeyen gelişmeler ve diğer yandan küreselleşmenin yaşamın hemen hemen her alanına etkisi sonucunda bireyler ve dolayısıyla toplumlar arası etkileşim ve iletişim önemli bir ihtiyaç hâlini almış 
durumdadır. Ülkeler arası sınırların sadece haritalardaki çizgilerden ibaret kaldığı günümüz dünyasında eğitim, ekonomi, politika vb. birçok alanda herhangi bir ülkede gelișen bir olay, durum, vb. artık coğrafi mesafeye bakılmaksızın birçok ülkeden anında takip edilebilmektedir. Toplumlar arası iletişimin bu derece yoğun ilerlediği çağımızda kültürel etkileşimin de kaçınılmaz bir durum olduğu ortadadır. Etkileşimin en temel aracının dil olduğu gerçeğinden yola çıkarak kültür ve dil bağlantısının önemi günümüzün çok kültürlü toplumlarında bu nedenle daha ön plana çıkmaktadır.

Dil kullanımında kültürün bu önemli etkisi ve işlevi yabancı dil öğretimi programlarına da yansımıştır. Yabancı dil öğretiminde artık Türkçeye eylem odaklı yaklaşım olarak çevrilen yöntem tercih edilmektedir. Avrupa Dilleri Ortak Başvuru Metni'nde amaçları ve ilkeleri detaylı şekilde açıklanmış olan eylem odaklı yaklaşım, dil kullanıcısını toplum içinde sözel iletişim ögeleriyle olduğu kadar sözsüz iletişim ögeleri ve davranışlarıyla da iletişim kuran sosyal bir aktör olarak kabul etmektedir. Bu çerçevede eylem odaklı yaklaşım bir yabancı dilin doğru ve etkili kullanılabilmesi için iletişim becerilerinin kazanılmasına öncelik veren bir yaklaşım olarak öne çıkmaktadır. Eylem odaklı yaklaşımda dil öğretimi sürecinde herhangi bir öğretici amaçla hazırlanmamış, tamamen doğal ve hedef dilin konuşulduğu toplum içinde gündelik hayatta kullanılan gerçek otantik dokümanlardan yararlanılmaktadır. Bunun nedeni yukarıda bahsedildiği gibi dil ve kültürün durağan olmayan ve yaşamın akışı içinde, çağın koşullarına göre değişebilen ve evrilebilen dinamik olgular olmasıdır.

Otantik dokümanlardan yararlanarak bireyin iletişim becerilerine odaklanan bu yabancı dil öğretimi yaklaşımında, temeli kültürel çeșitliliği korumaya dayanan kültürlerarası yaklaşım ile dil öğrenen bireylerde kültürlerarası iletişim becerisini geliştirmek hedeflenmektedir. Kültürlerarası iletişim becerisi bir yandan her bireyin kültürel farklılıklara karşı saygılı olmasını desteklerken diğer yandan bireyin nesnel bir bakış açısıyla kendi kültürel değerlerine karşı da farkındalık geliştirmesini amaçlamaktadır. Bireyde öncelikle kendi benimsediği değerler dıșında farklı değer ve gerçekliklerin olduğunu kabul etmekten yola çıkarak bireyin farklılıklara daha göreceli ve hoşgörülü bir bakış açısıyla bakması hedeflenmektedir.

Bu çalışmanın amacı, yabancı dil olarak Fransızca öğretim süreci kapsamındaki derslerde, öğrencilerde kültürlerarası iletişim becerisi geliştirmeyi hedefleyen ilke ve amaçlara uygun şekilde hazırlanmış bir uygulama örneği sunmaktır. Çalışmada öğrencilerin öğrenmekte oldukları hedef dil ile birlikte hedef kültürü de tanımlarına yönelik etkinlikler hazırlanmıştır. Çalışmada yararlanılan doküman, hedef kitlenin yaş, dil seviyesi, ilgi alanları gibi özelliklerine uygun olarak seçilmiştir. Diğer yandan doküman seçiminde, öğrenenlerin farklı dil becerilerini çalıştırabilecek ve ilgilerini, katılımlarını düşürmeyecek görsel ve işitsel özelliklerin bir arada olması kriteri göz önünde bulundurulmuştur. Tercih edilen doküman yayınlandığı dönemden beri orijinal dili olan Fransızcadan farklı dillere çevrilmiş ve geniş kitleler tarafindan beğenilerek izlenen bir filmdir. Seçilen film öğrencilere hedef kültürü olușturan Fransız toplumunu çok farklı boyutlarıyla gözlemleme imkânı sunarken aynı zamanda farklı eğitim sistemlerini tanımalarına katkı sağlamaktadır. Filmde aktarılan olaylar ve durumlar üzerinden, öğrencilerin kendi kültürlerine de farkındalık geliştirilmesi hedeflenirken, filmde yer alan karakterler üzerinden kültürlerarası iletişim yaklaşımında önem verilen farklılıklara karşı saygı, hoşgörü ve empati gibi kavramlar da ele alınmaktadır. Bu bakış açısıyla somut örnekler ve etkinliklerle insani değerlere karşı farkındalık oluşturmaya yardımcı olmaktadır.

Yabanc1 dil öğretimi derslerinde kültürlerarası iletişim becerisi geliştirmeye yönelik hazırlanmış bu uygulamanın, hem yabancı dil öğrencilerine hem yabancı dil eğitmenlerine bir yandan dil öğretimi sürecinde farklılıklara karşı saygılı ve kendi değerlerinin farkında olan bireyler yetiştirmek diğer yandan öğretilmekte/öğrenilmekte olan dili etkili ve doğru bir biçimde kullanımını sağlamak konusunda uygun bir örnek olacağı düşünülmektedir. 